\title{
Un asomo a la historia de la ciencia mexicana
}

José Luis Talancón

1.- En la época precolombina, el maguey constituyó una planta casi mágica muy importante para múltiples aplicaciones. De ella se obtenía papel, material de construcción, hilo, agujas, forrajes, pero particularmente se obtenía aguamiel, un jugo cuya fermentación produce el pulque.

La fermentación espontánea del aguamiel lo transforma en pulque a través de un proceso químico-biológico, igual al que convierte en vino el jugo de la uva. En aquella época esta bebida tenía un sentido profundamente religioso. En festividades lo bebían de manera ritual sacerdotes, ancianos, guerreros y enfermos, pues tiene propiedades curativas contra ciertas enfermedades intestinales.

Durante el período novohispano, perdió su carácter ritual y se convirtió en la bebida de consumo básica del pueblo mexicano. La Corona reglamentó su consumo, con fines moralistas y paternalistas para regular el alcoholismo de los indígenas, pero fundamentalmente con fines fiscales para fortalecer el erario público a partir de la comercialización de la bebida.

Como es bien sabido, se puede dividir la historia de la humanidad en dos períodos, la época en que la experiencia y la repetición eran las fuentes de conocimiento para transformar, procesar y fermentar durante miles de años las bebidas alcohólicas de una manera "natural" y espontánea y la época en que se sabe de la existencia de los microorganismos que pueden actuar favorablemente tanto en las fermentaciones y los destilados para obtener alcohol o los virus de comportamiento patógeno. Esta tarea se realizó bajo el concurso, la dirección y el conocimiento de los agentes bacteriológicos encargados de realizarlos bajo la observación científica.

La segunda época se inicia en México cuando comienzan a difundirse los éxitos del primer laboratorio bacteriológico en el Consejo Superior de Salubridad en 1888 para atacar la rabia. A partir de entonces y una vez que el micromundo fue una realidad accesible para varios científicos mexicanos, uno de los objetos de estudio inmediato fue precisamente el estudio de los actores que intervienen en la fermentación del pulque.

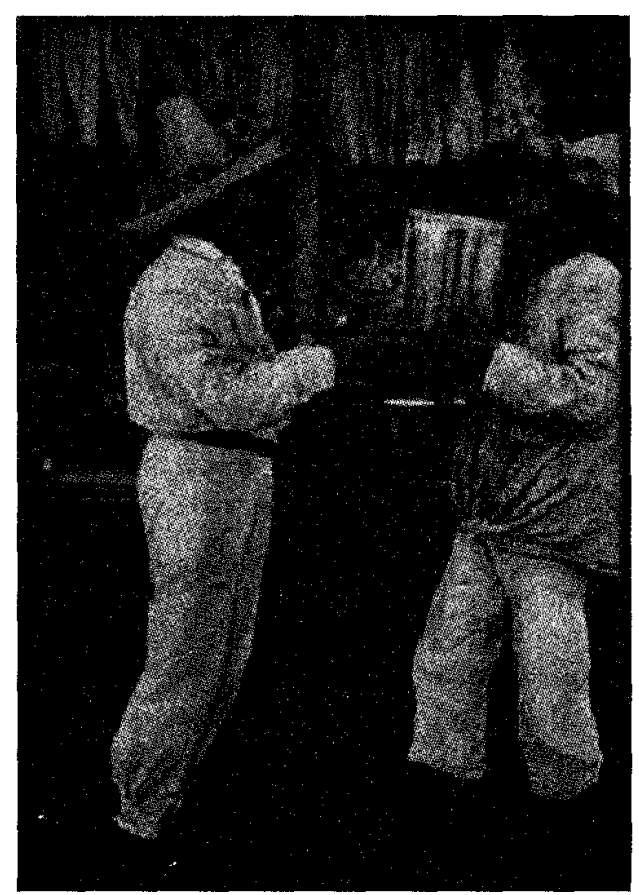

Hombres tomando pulque 
En este trabajo presento un estudio de caso atractivo para los historiadores de la ciencia química, en un período en el cual se asiste precisamente a esa transición caracterizada por la unión entre conocimientos técnicos que sirven de soporte y la intervención de conocimientos científicos, en la búsqueda por obtener un rendimiento industrial, gracias a un precursor de la bacteriología en México, el Dr. Antonio J. Carbajal.

2.- Antonio J. Carbajal era un estudiante de medicina hasta que se tituló en 1869 en la Escuela de Medicina y se forma profesionalmente en el Instituto Patológico en la sección de bacteriología. En 1897 viajó a Rusia y Alemania, en donde se hizo experto en zimotecnia y posteriormente estuvo en el Instituto Pasteur en donde se dedicó a estudiar las fermentaciones. En 1898 regresa a México y se dedica al estudio de las fermentaciones del pulque. Fue miembro de la Sociedad Agrícola Mexicana y de la Sociedad Científica Antonio Alzate.

Su afán por desarrollar la bacteriología del pulque lo lleva a afirmar "el estudio del pulque demanda una obra extensa experimental, la primera rigurosamente científica de laboratorio, la segunda especialmente técnica y de gran escala. Creo poseer la clave para escribirla." $Y$ en efecto fue el primero en lograr clasificar las levaduras del pulque las cuales la más interesante fue Saccha romyces cerevisiae agavica silvestre.

Junto con el El Dr. Liceaga, (otro científico que introdujo la noción de higiene urbana, y social), Antonio Carvajal será el encargado de efectuar la transición de la fermentación espontánea y empírica a la fermentación científica. Publicó en 1901 un Estudio sobre el pulque considerado principalmente desde el punto de vista zimotécnico y en 1911 -La fer- mentación racional del pulque-, publicaciones que ampliaron los conocimientos científicos del proceso y permitieron su refinamiento y tratamiento para obtener un mejor sabor y olor, lo que significó una paso fundamental de las haciendas al laboratorio-en la modernización de la producción de la bebida Inás arraigada en la tradicion del pueblo mexicano.

4.- Durante todo el siglo XIX, las haciendas fueron las unidades económicas basicas, dedicadas a una gran variedad de especialidades productivas, entre las que destacaban las haciendas pulqueras de los estados de Hidalgo, Tlaxcala, Puebla, Morelos y el estado de México. Su producción artesanal y empírica no permitía aumentos considerables en la producción y la ausencia de transportes eficaces dificultaba enormemente su comercialización regional. Esto permite el acuerdo entre los historiadores respecto al estancamiento que experimentó la economía del pulque en el período.

Sin embargo, con la introducción del ferrocarril a partir de 1863 (México-Apizaco) y principalmente al quedar concluida la vía México-Veracruz, el 1 de enero de 1873, la economía del pulque vive un auge que se refleja en la expansión del mercado principalmente en la ciudad de México, donde llegó a duplicarse el consumo en $11 \%$ entre los años de 1868 y 1884, duplicándose el número de pulquerías de 513 a más de mil.

La expansión de la producción comercial de las haciendas pulqueras no anuló la diversificación de los cultivos, porque el pulque dificilmente podía ser un producto de exportación nacional, por lo tanto, su mercado aunque estuviera en expansión era relativamente limitado en comparación con aquellos productos que sí rebasaban el mercado regional para abastecer el nacional. 
Para la primera década del siglo, eran varias haciendas las que surtían a la ciudad de México, pero en particular algunas de los estados mencionados, (El Rosario y Nuestra Señora de Guadalupe-Tepac y Mazaquiahuac) que se constituyeron en lo que fue la Compañía Expendedora de de Pulques, S.C.L. el 16 de marzo de 1909.

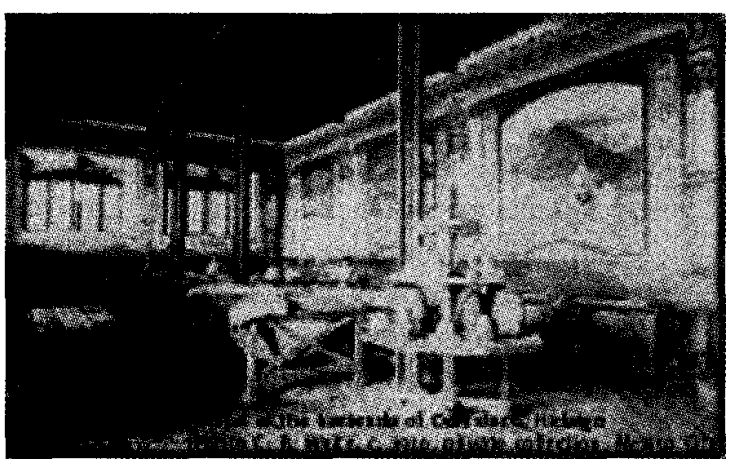

Tinacal, hacienda de Ometusco, Hidalgo

Sus socios estaban ligados a la producción y comercio del pulque. Uno de sus principales socios era Ignacio Torres Adalid que contaba con 109 expendios en la ciudad y cuatro haciendas. Se trataba de un monopolio que obtuvo grandes ventajas como mayorista y distribuidor, a través de su red de 851 pulquerías en la capital y con 138 en provincia. Llegó a tener bajo su control el $90 \%$ de las pulquerías establecidas en la capital.

Tenía negociaciones con el gobierno del D.F. encaminadas a evitar la entrada al mercado de otros productores, ocupar los puntos de venta más favorables, disminuir el número de pulquerias, con el objeto de eliminar las menos rentables e impedir la competencia entre casillas del mismo monopolio reduciendo a la vez costos redundantes de operación, etc., es decir, mantiene el perfil de empresa capitalista y monopólica típica del período.

Constituida por un Consejo de administración y Asamblea General la empresa incorpora un importante laboratorio zimotécnico gracias a las gestiones de Fernando Pimentel y Fagoaga a cuyo cargo nombran a nuestro personaje, el Dr. Antonio J. Carbajal.

El Dr. Carbajal encuentra que pese a todo el carácter capitalista de la empresa, sus procesos de extracción, transporte y producción del pulque se encuentran aún en una etapa muy rudimentaria y poco higiénica. Usaban levaduras y fermentos muy impuros, que limitaban el esfuerzo por elevar la productividad y calidad de la bebida.

Los métodos utilizados eran casi los mismos que los utilizados hacía mas de trescientos años: el tlachiquero recorría la tanda de magueyes para extraer el aguamiel succionándola de una cavidad abierta en el centro del agave, con un "acocote", calabaza grande alargada abierta en sus dos extremos y después de la succión, el tlachiquero "raspa" los tejidos de la cavidad, a fin de que no cicatricen y sigan manando miel.

El líquido recolectado en el acocote se trasvasa a unas pequeñas barricas de madera de 25 litros, que se acomodan al costado del burro y al concluir su recorrido se dirige a los "tinacales" con capacidad de 500 a 800 litros cada uno.

Observa que es posible purificar el aguarniel y el pulque, conocer la participación que cada especie tiene en la fermentación, introducir un fermento puro en una aguarniel absolutamente pura y obtener fermentaciones alcohólicas puras y corregir además las formas de extracción y transporte. 
En 1911, durante los mejores años de la empresa donde colabora publica el artículo ya citado La fermentación racional del pulque en la revista de la Sociedad científica Antonio Alzate, en el cual propone modernizar radicalmente el proceso de producción del pulque y aproximarse al ejemplo de compañías que al incorporar un saber científico a milenarios procesos técnicos, puede innovar y racionalizar los métodos productivos y expandirse al mercado nacional e internacional, como era el caso de compañías instaladas para producir la esencia artificial de violeta, la fabricación de cerveza en Alemania, el vino en Francia, el pan en Austria y la mantequilla y el queso en Holanda, gracias a la Zimotécnica, — como el la llamaba- o ciencia de las fermentaciones, con la cual es posible transitar hacia la modernización de la empresa, gracias al triunfo universal de la ciencia aplicada.

Lo que buscaba Carbajal era precisamente centralizar la fabricación de levaduras de laboratorio para ofrecerla al mercado pulquero. Toda su argumentación se dirige a favorecer el impacto que tendría la uilización racional de fermentos y bacterias en la fermentación del pulque, en detrimento de aquellos que preferían el pulque fermentado de manera empírica, tradicional, espontánea y rudimentaria. Claro, decía porque los pobres prefieren la cantidad a la calidad. (p. 225).

De lo que se trata es de producir centenares de levadura como cualquier agricultor podría producir millares de toneladas de trigo empleando las semillas de una clase determinada.

Los intentos por domesticar y racionalizar el comportamiento de la bacteria que hoy lleva su nombre Saccharomyces carbajalii, le llevaron la varios años de luchar por importar e insta- lar las piezas que conformaban el laboratorio: un esterilizador cuya fecha de pedido fue el 22 de marzo de 1910 y llegó a México el 26 de julio, un refrigerador que pidió en junio llegó de Copenhage en septiembre, un filtro que pidió en julio y llegó en octubre averiado, una bomba que solicitó en octubre y llegó en diciembre, todo esto se los cuento para dar una idea de las dificultades reales técnicas que implicaba montar un laboratorio con fines industriales en la primera etapa de industrialización del país.

Creó una sección de química donde se establecían las composiciones medias entre el aguamiel y el pulque, una sección de Biología donde se realizaba el aislamiento y caracterización de los principales microorganismos de la fermentación, especialmente de levaduras o fermentos alcohólicos y una sección industrial en donde tenía lugar la esterilización del aguamiel en grandes cantidades, lo cual le permitía transportado a grandes distancias y prepararlo en cantidades suficientes diversos fermentos especiales para lograr fermentaciones en gran escala.

En 1935 el Dr. Manuel Ruiz Oronoz estudió la misma levadura que el Dr. Antonio Carbajal y encontró que no era $S$. cerevisiae, sino una nueva especie, la cual dedicó al Dr. Carvajal, por lo que le dio el nombre de Saccharomyces carbajalii Es la levadura más interesante en el pulque y sobre ella se han efectuado numerosos trabajos, especialmente los del Dr. Sánchez Marroquí.

El Dr. Carbajal como científico vinculado a una empresa con grandes potencialidades tecnológicas y económicas se enfrentaba sin embargo a dos poderosos enemigos que no se le presentaban de manera evidente, uno era la inestabilidad política del país y otro de larga duración la industria cervecera. 
La expansión de la industria cervezera mexicana tiene que ver con este cambio de hábitos en el consumo, pues logró expulsar del mercado a la cerveza extranjera. Las importaciones de unos tres millones en el año fiscal $1889 \sqrt{1890}$ disminuyeron a poco más de 500 mil en 1910-1911, al tiempo que la demanda aumentaba.

La producción de la cervecería Cuauhtémoc en 1910 fue mas de 25 veces superior al volumen total de importaciones. Para 1906 la participación de la cerveza importada en el mercado había caído aproximadamente $4.96 \%$ de la demanda total. remplazar al pulque como la bebida favorita de la clase trabajadora, esta alteración se debía en gran parte a la publicidad masiva de los principales productores quienes desde el principio compitieron entre sí con base en las marcas comerciales y las calidad que los consumidores asociaban con éstas. Así por ejemplo, la cervecería Cuauhtémoc sacó bastante provecho del primer premio otorgado a la marca Carta Blanca en la feria mundial de San Luis Missouri en 1904. Sin embargo este cambio en los gustos no habría ocurrido si los ingresos no hubieran aumentado, sin considerar gran parte de la información convencional a cerca de las tendencias en los salarios reales en el Mé-
Al igual que otras empresas manufactueras la industria cervecera mexicana no sólo sustituía importaciones produciendolo loantes se importaba, sino que tambien habría un mercado completamente nuevo para un producto que nunca se había distribuido a tan gran escala.

Por ejemplo la producción de la cervecería Cuauhtémoc tan sólo en 1907 casi quintuplicó la cantidad de cerveza importada en el año de mayor actividad entre 1888 Y 1911.

En otras palabras, los gustos de los mexicanos comenzaban a cambiar en beneficio de la introducción de articulas modernos en lugar de los tradicionales, la cerveza empezaba a calmente lo que

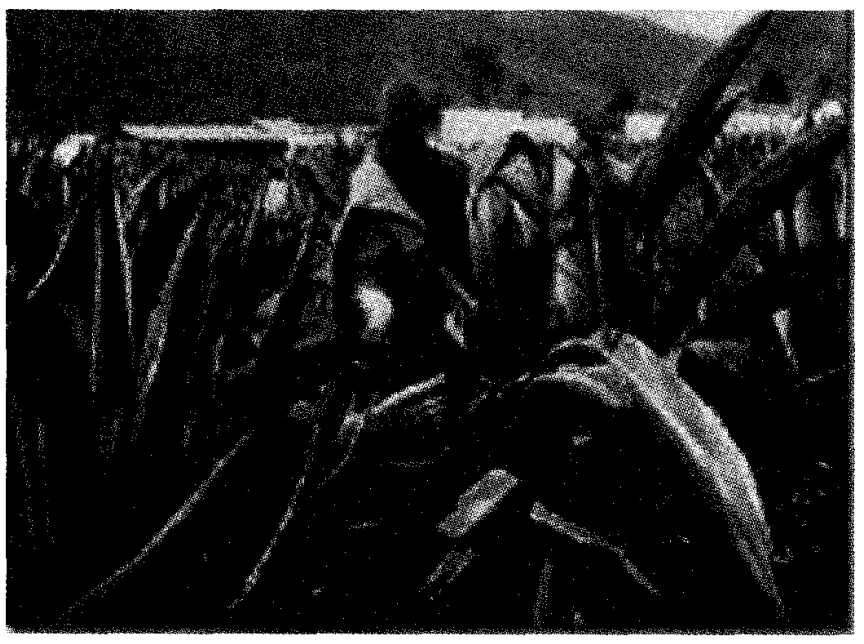

Hombre trabajando el maguey xico porfiriano; muy probablemente los ingresos efectivos de los trabajadores especialmente los calificados aumentaron durante todo el período de hecho; es dificil armonizar la caída en los salarios con una economía en desarrollo caracterizada por la escasez de mano de obra calificada.

\section{Conclusiones}

Existen actualmente 250 especies del género "agave", localizadas principalmente en la meseta central de la República Mexicana. De acuerdo al producto que puede extraerse de ella, suele dividirse en tres grandes grupos: Textileros, mescaleros y pulqueros. 
Un maguey produce aguamiel por un período que no excede los seis meses y durante ese tiempo aporta entre 500 y 1,000 litros. La cantidad y calidad depende del clima, la humedad y las condiciones del terreno.

Su transformación se realiza en el tinacal, la fase primordial del proceso consiste en vertir aguamiel fresco en una cierta cantidad de aguamiel ya fermentado (semilla). La fórmula para preparalo es un secreto del tinacalero quien debe tener gran experiencia para saber el momento adecuado para revolver la "semilla" con el aguamiel fresco (dar de comer).

Los recipientes o tinas más adecuadas para realizar las fermentaciones son las de cuero de res, aunque actualmente también se usan de material plástico.

Según su grado de fermentación se transforma en "tlachique", una bebida dulce con bajo contenido de alcohol $2^{\circ}$ o $4^{\circ} \mathrm{GL}$, ó pulque fuerte entre $5^{\circ}$ a $7^{\circ} \mathrm{GL}$.

Se trata de una bebida prerecedera siempre en fermentación y tanto por los tiempos de maduración del agave (5 a 10 años), como por sus técnicas rudimentarias de extracción, sus tiempos de fermentación verano (8 a 10 días), invierno ( 25 a 30 días), su producción ha sido siempre local y difícilmente comercializable a escala industrial.

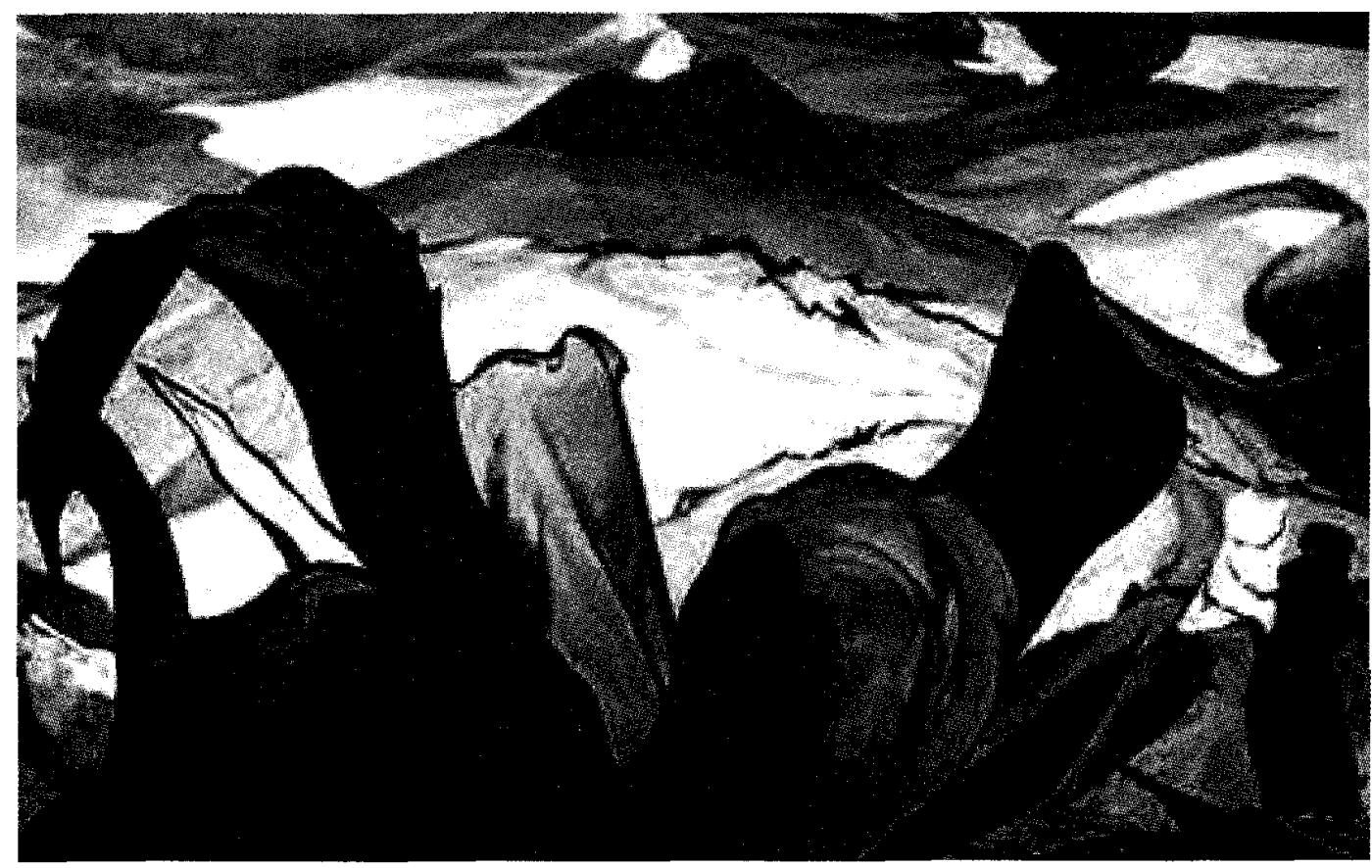

Paisaje con maguey de Pablo O'Higgins 